\title{
STUDI KASUS JAJANAN YANG MENGANDUNG BORAKS DAN FORMALIN DI TAMAN KURMA KOTA LUBUKLINGGAU
}

\author{
Nopa Nopiyanti ${ }^{1}$, Yuni Krisnawati ${ }^{2}$, Septi Heriani $^{3}$ \\ STKIP-PGRI Lubuklinggau ${ }^{1,2,3}$ \\ nopachandra@gmail.com ${ }^{1}$
}

\begin{abstract}
ABSTRAK
Penelitian ini bertujuan untuk mengetahui kandungan boraks dan formalin pada jajanan di Lingkungan Taman Kurma Kota Lubuklinggau. Jenis penelitian ini adalah deskriptif kualitatif. Objek dalam penelitian ini adalah sampel jajanan. Pengumpulan data dilakukan dengan observasi dan dokumentasi. Teknik analisis data secara deskriptif kualitatif dengan uji kandungan boraks dan formalin menggunakan tes kit. Perubahan warna kertas uji berwarna kuning menjadi warna merah kecoklatan maka sampel tersebut positif mengandung boraks dan perubahan warna cairan menjadi warna keunguan maka sampel tersebut positif mengandung formalin. Hasil uji kandungan boraks dan formalin dengan alat uji Tes Kit boraks dan Tes Kit formalin dari 187 sampel jajanan bahwa tidak terdapat sampel yang menggunakan boraks. Sedangkan hasil uji kandungan formalin terdapat 22 sampel yang menggunakan formalin yaitu Sosis terdapat 15 sampel, mie terdapat 2 sampel, bakso terdapat 4 sampel dan tahu terdapat 1 sampel. Berdasarkan hasil penelitian yang telah dilakukan, maka dapat disimpulkan bahwa, dari sampel jajanan yang diuji tidak terdapat sampel yang positif mengandung boraks. Sedangkan jajanan yang positif mengandung formalin, yaitu sosis, mie, bakso dan tahu goreng yang terdapat pada beberapa pedagang.
\end{abstract}

Kata Kunci: jajanan, boraks, formalin, dan tes kit.

\begin{abstract}
The research objective was to find out borax and formalin content in snacks at Lubuklinggau palm trees citypark. The research was a qualitative descriptive research with snacks samples as the object of the research. The data collection was conducted through observation and documentation. The data were analyzed qualitatively through borax and formalin test content by using test kit. The color change on yellow paper test turned into red brownies indicated a positive result of borax content and the color change in the liquid into purple indicated formalin content. The result of the test content with borax and formalin test kit on 187 samples showed the negative result on borax content. The test on formalin content indicated that there were 22 samples that use formalin such as 15 sausage samples, 2 noodle samples, 4 meatball samples and 1 tofu sample. Based on the research result, it can be concluded that the tested samples contain zero borax. In contrast, some snacks contain formalin, such as sausages, noodles, meatballs and fried tofu found at some street vendors.
\end{abstract}

Keywords: snacks, borax, formalin, test kit. 


\section{PENDAHULUAN}

Keamanan pangan merupakan upaya yang perlu diperhatikan untuk mencegah pangan dari bahan kimia yang dapat menganggu, merugikan serta membahayakan bagi kesehatan (Monijung, 2016). Obat dan makanan yang dimaksud terdiri atas obat, bahan obat, narkotika, psikotopika, prekursor, zat adiktif, obat tradisonal, suplemen kesehatan, kosmetik dan pangan olahan. Salah satu penyebab keracunan makanan adalah adanya bahan tambahan pangan berbahaya dalam makanan tersebut seperti boraks dan formalin (Paratmanitya \& Aprilia, 2016). Menurut Hidayat \& Muharrami (2014) bahwa formalin sangat berbahaya bila tertelan, karena dapat menyebabkan mulut, tenggorokan dan perut terasa terbakar. Selain itu juga dapat terjadi kerusakan pada hati, jantung, otak, dan ginjal.

Menurut Badan Pom RI (2014) bahwa boraks merupakan senyawa dengan nama kimia natrium tetraborat yang berbentuk kristal lunak. Boraks bila dilarutkan dalam air akan terurai menjadi natrium hidroksida dan asam borat. Sedangakn formalin adalah larutan yang tidak berwarna dan baunya sangat menyengat. Salah satu makanan yang banyak dan telah diketahui mengandung formalin adalah mie dan bakso. Beberapa jajanan lain yang berbahaya dan dapat mengancam kesehatan bagi para pembeli, diantaranya yaitu model, pempek, nugget, sayap, ati, usus, keong, ceker, kepala ayam, sosis, jamur crispy, sate, soto, gorengan (tahu, tempe, pisang, bakwan, risol, tempe), capucino cincau, tela-tela, piscok, roti bakar, kwitiau, kebab, molen, onde-onde, bandrek, sop buah, es kacang merah, somai dan ketoprak.

Berdasarkan uji pendahuluan dengan menggunakan Tes Kit Boraks dan Tes Kit Formalin yang dilakukan terhadap beberapa jajanan yaitu bakso, nugget, model dan mie yang diambil dari pedagang yang berbeda, pada tanggal 10 Mei 2018 di Taman Kurma Kota Lubuklinggau. Dari hasil uji pendahuluan didapatkan dua objek jajanan yang mengandung bahan tambahan pangan berupa formalin. Hal ini terlihat dari perubahan warna jajanan yang menjadi warna ungu. Bahaya kandungan formalin pada jajanan tersebut menjadi kekhawatiran masyarakat, sehingga masyarakat perlu dilindungi dari penggunaan bahan tambahan pangan yang tidak memenuhi persyaratan kesehatan. Oleh karena itu, perlunya pengetahuan masyarakat tentang bahaya jajanan yang mengandung formalin yang dapat mengancam kesehatan bagi tubuh manusia.

\section{METODE PENELITIAN}

Jenis penelitian ini adalah penelitian deskriptif dengan metode yang digunakan adalah metode kualitatif. Pengumpulan data ini terdiri dari observasi lokasi penelitian sebagai tahap persiapan, sedangkan pada tahap pelaksanaan peneliti melakukan pengambilan sampel serta dokumentasi 


\section{Prosedur Penelitian}

Uji Kandungan Boraks

Menurut Pandie (2014), uji kandungan boraks dilakukan dengan cara sebagai berikut:

1. Sampel ditimbang sebanyak 5 gram secara steril kemudian dihaluskan.

2. Air panas ditambah kedalam sampel sebanyak $10 \mathrm{ml}$ kemudian diaduk hingga tercampur.

3. $\mathrm{HCl} 5 \%$ sebanyak $5 \mathrm{ml}$ kemudian diteteskan Reagen pengujuian boraks sebanyak 10 tetes.

4. Sampel diaduk hingga tercampur lalu celupkan kertas pengujian sampai terendam sebagian.

5. Kertas pengujian dikeringkan dan lihat perubahan warna yang terjadi pada kertas tersebut. Apabila berbentuk warna merah bata maka sampel tersebut mengandung boraks.

Uji Kandungan Formalin

Menurut Pandie (2014), uji kandungan formalin dilakukan dengan cara sebagai berikut:

1. Sampel ditimbang sebanyak 10 gram secara aseptik, kemudian dimasukkan ke dalam wadah steril.

2. Sampel dicincang kecil-kecil dan dihaluskan dengan mortal.

3. Air panas ditambahkan sebanyak $20 \mathrm{ml}$ dan diaduk kemudian dibiarkan sampai dingin.

4. Air campuran tersebut diambil sebanyak $5 \mathrm{ml}$ kemudian diteteskan menggunakan Reagent A dan Reagent B masing-masing sebanyak 4 tetes, dikocok dan dibiarkan selama 5 sampai 10 menit.

5. Apabila sampel berubah warna menjadi warna ungu maka sampel tersebut mengandung formalin. Menurut Suntaka (2014), yang menyatakan bahwa adanya perubahan warna yang terjadi dari transparan menjadi warna pink keunguan setelah ditetesi dengan reagent $\mathrm{A}$ dan reagent $\mathrm{B}$.

\section{HASIL PENELITIAN}

\section{Hasil Uji Kandungan Boraks dan Formalin Menggunakan Tes Kit}

Pengujian kandungan boraks dan formalin pada 187 sampel jajanan dengan menggunakan Tes Kit Boraks dan Tes Kit Formalin, dengan melihat perubahan warna kertas uji berwarna kuning menjadi warna merah kecoklatan maka sampel tersebut positif mengandung boraks dan dengan melihat perubahan warna cairan menjadi warna keunguan maka sampel tersebut positif mengandung formalin. Hasil uji kandungan boraks dan formalin dapat dilihat pada Tabel di bawah ini: 
Tabel 1 Hasil Uji Kandungan Boraks dan Formalin Pada Jajanan

\begin{tabular}{|c|c|c|c|c|c|c|}
\hline \multirow[b]{2}{*}{ No. } & \multirow{2}{*}{$\begin{array}{c}\text { Lokasi } \\
\text { Pengambilan } \\
\text { Sampel } \\
\end{array}$} & \multirow{2}{*}{\multicolumn{2}{|c|}{ Sampel Jajanan }} & \multicolumn{2}{|c|}{ Hasil Uji } & \multirow[b]{2}{*}{ Keterangan } \\
\hline & & & & Boraks & Formalin & \\
\hline \multirow[t]{4}{*}{1.} & \multirow[t]{4}{*}{ Pedagang 1} & 1. & Bakso Kuah & - & - & Tidak Ada \\
\hline & & 2. & Mie Ayam & - & - & Tidak Ada \\
\hline & & 3. & Pempek & - & - & Tidak Ada \\
\hline & & 4. & Model & - & - & Tidak Ada \\
\hline 2. & Pedagang 2 & 5. & Sate & - & - & Tidak Ada \\
\hline 3. & Pedagang 3 & 6. & Capucinno Cincau & - & - & Tidak Ada \\
\hline \multirow[t]{2}{*}{4.} & \multirow[t]{2}{*}{ Pedagang 4} & 7. & Jamur Crispy & - & - & Tidak Ada \\
\hline & & 8. & Tela-Tela & - & - & Tidak Ada \\
\hline 5. & Pedagang 5 & 9. & Piscok & - & - & Tidak Ada \\
\hline 6. & Pedagang 6 & 10. & Roti Bakar & - & - & Tidak Ada \\
\hline 7. & Pedagang 7 & 11. & Capucino Cincau & - & - & Tidak Ada \\
\hline \multirow[t]{8}{*}{8.} & \multirow[t]{8}{*}{ Pedagang 8} & 12. & Bakso Bakar & - & - & Tidak Ada \\
\hline & & 13. & Ati & - & - & Tidak Ada \\
\hline & & 14. & Usus & - & - & Tidak Ada \\
\hline & & 15. & Ceker & - & - & Tidak Ada \\
\hline & & 16. & Keong & - & - & Tidak Ada \\
\hline & & 17. & Sayap & - & - & Tidak Ada \\
\hline & & 18. & Kepala Ayam & - & - & Tidak Ada \\
\hline & & 19. & Sosis & - & + & $\begin{array}{c}\text { Terjadi perubahan } \\
\text { warna menjadi warna } \\
\text { pink keunguan terang }\end{array}$ \\
\hline \multirow[t]{2}{*}{9.} & \multirow[t]{2}{*}{ Pedagang 9} & 20. & Mie Tumis & - & - & Tidak Ada \\
\hline & & 21. & Kwitiau & - & - & Tidak Ada \\
\hline 10. & Pedagang 10 & 22. & Capucino Cincau & - & - & Tidak Ada \\
\hline 11. & Pedagang 11 & 23. & Kebab & - & - & Tidak Ada \\
\hline \multirow[t]{2}{*}{12.} & \multirow[t]{2}{*}{ Pedagang 12} & 24. & Molen & - & - & Tidak Ada \\
\hline & & 25. & Onde-Onde & - & - & Tidak Ada \\
\hline 13. & Pedagang 13 & 26. & Capucino Cincau & - & - & Tidak Ada \\
\hline 14. & Pedagang 14 & 27. & Bandrek & - & - & Tidak Ada \\
\hline 15. & Pedagang 15 & 28. & Soto & - & - & Tidak Ada \\
\hline \multirow[t]{5}{*}{16.} & \multirow[t]{5}{*}{ Pedagang 16} & 29. & Tahu Goreng & - & - & Tidak Ada \\
\hline & & 30. & Tempe Goreng & - & - & Tidak Ada \\
\hline & & 31. & Pisang Goreng & - & - & Tidak Ada \\
\hline & & 32. & Bakwan & - & - & Tidak Ada \\
\hline & & 33. & Risol & - & - & Tidak Ada \\
\hline \multirow[t]{8}{*}{17.} & \multirow[t]{8}{*}{ Pedagang 17} & 34. & Bakso Bakar & - & - & Tidak Ada \\
\hline & & 35. & Ati & - & - & Tidak Ada \\
\hline & & 36. & Usus & - & - & Tidak Ada \\
\hline & & 37. & Ceker & - & - & Tidak Ada \\
\hline & & & Keong & - & - & Tidak Ada \\
\hline & & 39. & Sayap & - & - & Tidak Ada \\
\hline & & 40. & Kepala Ayam & - & - & Tidak Ada \\
\hline & & 41. & Sosis & - & + & $\begin{array}{c}\text { Terjadi perubahan } \\
\text { warna menjadi warna } \\
\text { pink keunguan terang }\end{array}$ \\
\hline 18. & Pedagang 18 & 42. & Capucino Cincau & - & - & Tidak Ada \\
\hline 19. & Pedagang 19 & 43. & Capucino Cincau & - & - & Tidak Ada \\
\hline 20. & Pedagang 20 & 44. & Capucino Cincau & - & - & Tidak Ada \\
\hline 21. & Pedagang 21 & 45. & Capucino Cincau & - & - & Tidak Ada \\
\hline 22. & Pedagang 22 & 46. & Piscok & - & - & Tidak Ada \\
\hline 23. & Pedagang 23 & 47. & Bakso Bakar & - & - & Tidak Ada \\
\hline
\end{tabular}




\begin{tabular}{|c|c|c|c|c|c|c|}
\hline \multirow{9}{*}{ No. } & \multirow{9}{*}{$\begin{array}{c}\text { Lokasi } \\
\text { Pengambilan } \\
\text { Sampel }\end{array}$} & \multirow{2}{*}{\multicolumn{2}{|c|}{ Sampel Jajanan }} & \multicolumn{2}{|c|}{ Hasil Uji } & \multirow[b]{2}{*}{ Keterangan } \\
\hline & & & & Boraks & Formalin & \\
\hline & & 48. & Ati & - & - & Tidak Ada \\
\hline & & 49. & Usus & - & - & Tidak Ada \\
\hline & & 50. & Ceker & - & - & Tidak Ada \\
\hline & & 51. & Keong & - & - & Tidak Ada \\
\hline & & 52. & Sayap & - & - & Tidak Ada \\
\hline & & 53. & Kepala Ayam & - & - & Tidak Ada \\
\hline & & 54. & Sosis & - & + & $\begin{array}{c}\text { Terjadi perubahan } \\
\text { warna menjadi warna } \\
\text { pink keunguan terang }\end{array}$ \\
\hline 24. & Pedagang 24 & 55. & Capucino Cincau & - & - & Tidak Ada \\
\hline 25. & Pedagang 25 & 56. & Capucino Cincau & - & - & Tidak Ada \\
\hline \multirow[t]{8}{*}{26.} & \multirow[t]{8}{*}{ Pedagang 26} & 57. & Bakso Bakar & - & - & Tidak Ada \\
\hline & & 58. & Ati & - & - & Tidak Ada \\
\hline & & 59. & Usus & - & - & Tidak Ada \\
\hline & & 60. & Ceker & - & - & Tidak Ada \\
\hline & & 61. & Keong & - & - & Tidak Ada \\
\hline & & 62. & Sayap & - & - & Tidak Ada \\
\hline & & 63. & Kepala Ayam & - & - & Tidak Ada \\
\hline & & 64. & Sosis & - & + & $\begin{array}{c}\text { Terjadi perubahan } \\
\text { warna menjadi warna } \\
\text { pink keunguan terang }\end{array}$ \\
\hline 27. & Pedagang 27 & 65. & Sop Buah & - & - & Tidak Ada \\
\hline 28. & Pedagang 28 & 66. & Capucino Cincau & - & - & Tidak Ada \\
\hline \multirow[t]{9}{*}{29.} & \multirow[t]{9}{*}{ Pedagang 29} & 67. & Bakso Bakar & - & - & Tidak Ada \\
\hline & & 68. & Ati & - & - & Tidak Ada \\
\hline & & 69. & Usus & - & - & Tidak Ada \\
\hline & & 70. & Ceker & - & - & Tidak Ada \\
\hline & & 71. & Keong & - & - & Tidak Ada \\
\hline & & 72. & Sayap & - & - & Tidak Ada \\
\hline & & 73. & Kepala Ayam & - & - & Tidak Ada \\
\hline & & 74. & Sosis & - & + & $\begin{array}{c}\text { Terjadi perubahan } \\
\text { warna menjadi warna } \\
\text { pink keunguan terang }\end{array}$ \\
\hline & & 75. & Nugget & - & - & Tidak Ada \\
\hline 30. & Pedagang 30 & 76. & Es Kacang Merah & - & - & Tidak Ada \\
\hline 31. & Pedagang 31 & 77. & Capucino Cincau & - & - & Tidak Ada \\
\hline 32. & Pedagang 32 & 78. & Sop Buah & - & - & Tidak Ada \\
\hline \multirow[t]{2}{*}{33.} & \multirow[t]{2}{*}{ Pedagang 33} & 79. & Mie Ayam & - & + & $\begin{array}{c}\text { Terjadi perubahan } \\
\text { warna menjadi warna } \\
\text { pink keunguan pekat }\end{array}$ \\
\hline & & 80. & Bakso Kuah & - & + & $\begin{array}{c}\text { Terjadi perubahan } \\
\text { warna menjadi warna } \\
\text { pink keunguan terang }\end{array}$ \\
\hline \multirow[t]{2}{*}{34.} & \multirow[t]{2}{*}{ Pedagang 34} & 81. & Pempek & - & - & Tidak Ada \\
\hline & & 82. & Model & - & - & Tidak Ada \\
\hline \multirow[t]{8}{*}{35.} & \multirow[t]{8}{*}{ Pedagang 35} & 83. & Bakso Bakar & - & - & Tidak Ada \\
\hline & & 84. & Ati & - & - & Tidak Ada \\
\hline & & 85. & Usus & - & - & Tidak Ada \\
\hline & & 86. & Ceker & - & - & Tidak Ada \\
\hline & & 87. & Keong & - & - & Tidak Ada \\
\hline & & 88. & Sayap & - & - & Tidak Ada \\
\hline & & 89. & Kepala Ayam & - & - & Tidak Ada \\
\hline & & 90. & Sosis & - & + & Terjadi perubahan \\
\hline
\end{tabular}




\begin{tabular}{|c|c|c|c|c|c|c|}
\hline \multirow{3}{*}{ No. } & \multirow{3}{*}{$\begin{array}{c}\text { Lokasi } \\
\text { Pengambilan } \\
\text { Sampel }\end{array}$} & \multirow{2}{*}{\multicolumn{2}{|c|}{ Sampel Jajanan }} & \multicolumn{2}{|c|}{ Hasil Uji } & \multirow[b]{2}{*}{ Keterangan } \\
\hline & & & & Boraks & Formalin & \\
\hline & & & & & & $\begin{array}{l}\text { warna menjadi warna } \\
\text { pink keunguan terang }\end{array}$ \\
\hline 36. & Pedagang 36 & 91. & Capucino Cincau & - & - & Tidak Ada \\
\hline \multirow[t]{8}{*}{37.} & Pedagang 37 & 92. & Bakso Bakar & - & + & $\begin{array}{c}\text { Terjadi perubahan } \\
\text { warna menjadi warna } \\
\text { pink keunguan terang }\end{array}$ \\
\hline & & 93. & Ati & - & - & Tidak Ada \\
\hline & & 94. & Usus & - & - & Tidak Ada \\
\hline & & 95. & Ceker & - & - & Tidak Ada \\
\hline & & 96. & Keong & - & - & Tidak Ada \\
\hline & & 97. & Sayap & - & - & Tidak Ada \\
\hline & & 98. & Kepala Ayam & - & - & Tidak Ada \\
\hline & & 99. & Sosis & - & + & $\begin{array}{c}\text { Terjadi perubahan } \\
\text { warna menjadi warna } \\
\text { pink keunguan terang }\end{array}$ \\
\hline 38. & Pedagang 38 & 100. & Sop Buah & - & - & Tidak Ada \\
\hline \multirow[t]{8}{*}{39.} & Pedagang 39 & 101. & Bakso Bakar & - & - & Tidak Ada \\
\hline & & 102. & Ati & - & - & Tidak Ada \\
\hline & & 103. & Usus & - & - & Tidak Ada \\
\hline & & 104. & Ceker & - & - & Tidak Ada \\
\hline & & 105. & Keong & - & - & Tidak Ada \\
\hline & & 106. & Sayap & - & - & Tidak Ada \\
\hline & & 107. & Kepala Ayam & - & - & Tidak Ada \\
\hline & & 108. & Sosis & - & + & $\begin{array}{c}\text { Terjadi perubahan } \\
\text { warna menjadi warna } \\
\text { pink keunguan terang }\end{array}$ \\
\hline 40. & Pedagang 40 & 109. & Somai & - & - & Tidak Ada \\
\hline \multirow[t]{2}{*}{41.} & Pedagang 41 & 110. & Mie Ayam & - & - & Tidak Ada \\
\hline & & 111. & Bakso Kuah & - & - & Tidak Ada \\
\hline 42. & Pedagang 42 & 112. & Model & - & - & Tidak Ada \\
\hline 43. & Pedagang 43 & 113. & Soto & - & - & Tidak Ada \\
\hline \multirow[t]{8}{*}{44.} & Pedagang 44 & 114. & Bakso Bakar & - & + & $\begin{array}{c}\text { Terjadi perubahan } \\
\text { warna menjadi warna } \\
\text { pink keunguan pudar }\end{array}$ \\
\hline & & 115. & Ati & - & - & Tidak Ada \\
\hline & & 116. & Usus & - & - & Tidak Ada \\
\hline & & 117. & Ceker & - & - & Tidak Ada \\
\hline & & 118. & Keong & - & - & Tidak Ada \\
\hline & & 119. & Sayap & - & - & Tidak Ada \\
\hline & & 120. & Kepala Ayam & - & - & Tidak Ada \\
\hline & & 121. & Sosis & - & + & $\begin{array}{c}\text { Terjadi perubahan } \\
\text { warna menjadi warna } \\
\text { pink keunguan terang }\end{array}$ \\
\hline \multirow[t]{3}{*}{45.} & Pedagang 45 & 122. & Mie Ayam & - & - & Tidak Ada \\
\hline & & 123. & Soto & - & - & Tidak Ada \\
\hline & & 124. & Ketoprak & - & - & Tidak Ada \\
\hline \multirow[t]{7}{*}{46.} & Pedagang 46 & 125. & Bakso Bakar & - & - & Tidak Ada \\
\hline & & 126. & Ati & - & - & Tidak Ada \\
\hline & & 127. & Usus & - & - & Tidak Ada \\
\hline & & 128. & Ceker & - & - & Tidak Ada \\
\hline & & 129. & Keong & - & - & Tidak Ada \\
\hline & & 130. & Sayap & - & - & Tidak Ada \\
\hline & & 131. & Kepala Ayam & - & - & Tidak Ada \\
\hline
\end{tabular}




\begin{tabular}{|c|c|c|c|c|c|c|}
\hline \multirow{3}{*}{ No. } & \multirow{3}{*}{$\begin{array}{c}\text { Lokasi } \\
\text { Pengambilan } \\
\text { Sampel }\end{array}$} & \multirow{2}{*}{\multicolumn{2}{|c|}{ Sampel Jajanan }} & \multicolumn{2}{|c|}{ Hasil Uji } & \multirow[b]{2}{*}{ Keterangan } \\
\hline & & & & Boraks & Formalin & \\
\hline & & 132. & Sosis & - & + & $\begin{array}{c}\text { Terjadi perubahan } \\
\text { warna menjadi warna } \\
\text { pink keunguan terang }\end{array}$ \\
\hline \multirow[t]{8}{*}{47.} & \multirow[t]{8}{*}{ Pedagang 47} & 133. & Bakso Bakar & - & - & Tidak Ada \\
\hline & & 134. & Ati & - & - & Tidak Ada \\
\hline & & 135. & Usus & - & - & Tidak Ada \\
\hline & & 136. & Ceker & - & - & Tidak Ada \\
\hline & & 137. & Keong & - & - & Tidak Ada \\
\hline & & 138. & Sayap & - & - & Tidak Ada \\
\hline & & 139. & Kepala Ayam & - & - & Tidak Ada \\
\hline & & 140. & Sosis & - & + & $\begin{array}{c}\text { Terjadi perubahan } \\
\text { warna menjadi warna } \\
\text { pink keunguan terang }\end{array}$ \\
\hline \multirow[t]{8}{*}{48.} & \multirow[t]{8}{*}{ Pedagang 48} & 141. & Bakso Bakar & - & - & Tidak Ada \\
\hline & & 142. & Ati & - & - & Tidak Ada \\
\hline & & 143. & Usus & - & - & Tidak Ada \\
\hline & & 144. & Ceker & - & - & Tidak Ada \\
\hline & & 145. & Keong & - & - & Tidak Ada \\
\hline & & 146. & Sayap & - & - & Tidak Ada \\
\hline & & 147. & Kepala Ayam & - & - & Tidak Ada \\
\hline & & 148. & Sosis & - & + & $\begin{array}{c}\text { Terjadi perubahan } \\
\text { warna menjadi warna } \\
\text { pink keunguan terang }\end{array}$ \\
\hline 49. & Pedagang 49 & 149. & Capucino Cincau & - & - & Tidak Ada \\
\hline \multirow[t]{2}{*}{50.} & \multirow[t]{2}{*}{ Pedagang 50} & 150. & Capucino Cincau & - & - & Tidak Ada \\
\hline & & 151. & Model & - & - & Tidak Ada \\
\hline \multirow[t]{8}{*}{51.} & \multirow[t]{8}{*}{ Pedagang 51} & 152. & Bakso Bakar & - & - & Tidak Ada \\
\hline & & 153. & Ati & - & - & Tidak Ada \\
\hline & & 154. & Usus & - & - & Tidak Ada \\
\hline & & 155. & Ceker & - & - & Tidak Ada \\
\hline & & 156. & Keong & - & - & Tidak Ada \\
\hline & & 157. & Sayap & - & - & Tidak Ada \\
\hline & & 158. & Kepala Ayam & - & - & Tidak Ada \\
\hline & & 159. & Sosis & - & + & $\begin{array}{c}\text { Terjadi perubahan } \\
\text { warna menjadi warna } \\
\text { pink keunguan terang }\end{array}$ \\
\hline \multirow[t]{8}{*}{52.} & \multirow[t]{8}{*}{ Pedagang 52} & 160. & Bakso Bakar & - & + & $\begin{array}{c}\text { Terjadi perubahan } \\
\text { warna menjadi warna } \\
\text { pink keunguan pudar }\end{array}$ \\
\hline & & 161. & Ati & - & - & Tidak Ada \\
\hline & & 162. & Usus & - & - & Tidak Ada \\
\hline & & 163. & Ceker & - & - & Tidak Ada \\
\hline & & 164. & Keong & - & - & Tidak Ada \\
\hline & & 165. & Sayap & - & - & Tidak Ada \\
\hline & & 166. & Kepala Ayam & - & - & Tidak Ada \\
\hline & & 167. & Sosis & - & + & $\begin{array}{c}\text { Terjadi perubahan } \\
\text { warna menjadi warna } \\
\text { pink keunguan terang }\end{array}$ \\
\hline \multirow[t]{5}{*}{53.} & \multirow[t]{5}{*}{ Pedagang 53} & 168. & Bakso Bakar & - & - & Tidak Ada \\
\hline & & 169. & Ati & - & - & Tidak Ada \\
\hline & & 170. & Usus & - & - & Tidak Ada \\
\hline & & 171. & Ceker & - & - & Tidak Ada \\
\hline & & 172. & Keong & - & - & Tidak Ada \\
\hline
\end{tabular}




\begin{tabular}{|c|c|c|c|c|c|c|}
\hline \multirow{6}{*}{ No. } & \multirow{6}{*}{$\begin{array}{c}\text { Lokasi } \\
\text { Pengambilan } \\
\text { Sampel }\end{array}$} & \multirow{2}{*}{\multicolumn{2}{|c|}{ Sampel Jajanan }} & \multicolumn{2}{|c|}{ Hasil Uji } & \multirow[b]{2}{*}{ Keterangan } \\
\hline & & & & Boraks & Formalin & \\
\hline & & 173. & Sayap & - & - & Tidak Ada \\
\hline & & 174. & Kepala Ayam & - & - & Tidak Ada \\
\hline & & 175. & Sosis & - & + & $\begin{array}{c}\text { Terjadi perubahan } \\
\text { warna menjadi warna } \\
\text { pink keunguan terang }\end{array}$ \\
\hline & & 176. & Nugget & - & - & Tidak Ada \\
\hline \multirow[t]{2}{*}{54.} & Pedagang 54 & 177. & Soto & - & - & Tidak Ada \\
\hline & & 178. & Lotek & - & - & Tidak Ada \\
\hline 55. & Pedagang 55 & 179. & Pempek Pangang & - & - & Tidak Ada \\
\hline \multirow[t]{5}{*}{56.} & Pedagang 56 & 180. & Tahu Goreng & - & + & $\begin{array}{c}\text { Terjadi perubahan } \\
\text { warna menjadi warna } \\
\text { pink keunguan terang }\end{array}$ \\
\hline & & 181. & Tempe Goreng & - & - & Tidak Ada \\
\hline & & 182. & Pisang Goreng & - & - & Tidak Ada \\
\hline & & 183. & Bakwan & - & - & Tidak Ada \\
\hline & & 184. & Risol & - & - & Tidak Ada \\
\hline 57. & Pedagang 57 & 185. & Sate & - & - & Tidak Ada \\
\hline 58. & Pedagang 58 & 186. & Sate & - & - & Tidak Ada \\
\hline 59. & Pedagang 59 & 187. & Mie Tumis & - & + & $\begin{array}{c}\text { Terjadi perubahan } \\
\text { warna menjadi warna } \\
\text { pink keunguan terang }\end{array}$ \\
\hline
\end{tabular}

Keterangan : + : Positif mengandung boraks atau formalin

- : Negatif mengandung boraks atau formalin

\section{PEMBAHASAN}

Uji kandungan boraks pada sampel jajanan yang dideteksi dengan menggunakan Tes Kit Boraks pada 187 sampel jajanan yang diambil di lingkungan Taman Kurma Kota Lubuklinggau. Sampel yang positif mengandung boraks ditandai dengan terjadinya perubahan warna pada kertas uji dari warna kuning menjadi warna merah kecoklatan. Pernyataan ini sesuai menurut Muharrami (2014) yang menyatakan bahwa perubahan warna kurkumin tersebut dari kuning menjadi merah kecoklatan.

Berdasarkan hasil penelitian dari 187 sampel yang diuji dengan menggunakan Tes Kit Boraks, bahwa tidak terjadi perubahan warna menjadi merah kecoklatan. Hal ini dikarenakan sampel jajanan yang diuji tidak terjadi perubahan warna pada kertas uji. Menurut Mayasari (2012), boraks merupakan suatu senyawa yang berbentuk kristal, warna putih, tidak berbau, larut dalam air dan stabil pada suhu dan tekanan normal. Boraks biasanya digunakan untuk pengawet, sebagai antiseptik dan pembasmi kecoa. Namun boraks sering disalahgunakan sebagai bahan tambahan makanan untuk menambah rasa dan keawetan makanan.

Uji kandungan formalin pada sampel jajanan yang dideteksi dengan menggunakan Tes Kit Formalin pada 187 sampel jajanan yang diambil di lingkungan Taman Kurma Kota Lubuklinggau. Sampel yang positif mengandung formalin ditandai dengan terjadinya perubahan warna cairan menjadi pink 
keunguan setelah ditetesi dengan reagent A dan reagent $\mathrm{B}$. Hal ini menandakan bahwa adanya kandungan formalin yang terdapat pada sampel.

Berdasarkan hasil penelitian dari 187 sampel yang diuji dengan menggunakan Tes Kit Formalin, bahwa terdapat 22 sampel yang positif mengandung formalin, yaitu terdapat pada sampel sosis yang berjumlah 15 sampel yang terdeteksi mengandung formalin yang ditandai dengan adanya perubahan warna pink keunguan terang pada sampel cairan setelah ditetesi reagent A dan reagent $\mathrm{B}$. Warna yang dihasilkan pink keunguan terang diduga karena konsentrasi formalin dalam sosis tidak terlalu tinggi.

Kedua, sampel mie ayam 1 sampel dan mi tumis 1 sampel yang terdeteksi mengandung formalin ditandai dengan adanya perubahan warna pink keunguan pekat pada sampel cairan yang ditetesi reagent A dan reagent B. Warna yang dihasilkan pink keunguan pekat diduga karena konsentrasi formalin dalam mie ayam terlalu tinggi.

Ketiga pada sampel bakso kuah yang berjumlah 2 sampel yang terdeteksi mengandung formalin yang ditandai dengan adanya perubahan warna pink keunguan terang pada sampel cairan yang ditetesi reagent $\mathrm{A}$ dan reagent $\mathrm{B}$. sedangkan pada bakso bakar berjumlah 2 sampel yang terdeteksi mengandung formalin yang ditandai dengan adanya perubahan warna pink keunguan pudar pada sampel cairan setelah ditetesi reagent A dan reagent B. Warna yang dihasilkan pink keunguan pudar diduga karena konsentrasi formalin dalam bakso bakar rendah.

Keempat, pada sampel tahu goreng berjumlah 1 sampel yang terdeteksi mengandung formalin yang ditandai dengan adanya perubahan warna pink keunguan terang pada sampel cairan setelah ditetesi reagent $\mathrm{A}$ dan reagent $\mathrm{B}$. Warna yang dihasilkan pink keunguan terang diduga karena konsentrasi formalin dalam tahu goreng tidak terlalu tinggi.

Dari hasil uji kandungan formalin pada jajanan yang didapatkan hasil yang berbeda setiap sampel yang berubah warna pink keunguan pekat, pink keunguan terang dan pink keunguan pudar, dapat disimpulkan bahwa kadar pada setiap sampel berbeda dari satu dengan yang lainnya. Menurut hasil penelitian Junaini (2016), menyatakan bahwa warna yang dihasilkan setelah penambahan tes kit antilin bervariasi sesuai dengan variasi konsentrasi sampel yang dihasilkan. Warna yang dihasilkan berbanding lurus dengan konsentrasi sampel dimana semakin tinggi konsentrasi sampel maka warna yang dihasilkan semakin ungu.

Makanan yang mengandung boraks dan formalin dalam kadar serendah apapun akan berdampak berbahaya terhadap kesehatan. Jika boraks dan formalin masuk ke dalam tubuh secara rutin dan terus menerus akan mengakibatkan penumpukan pada tubuh. Secara umum dampak penggunaan boraks dan formalin pada manusia dapat menurunkan derajat kesehatan dan kemampuan daya tahan tubuh hidup manusia (Mudzkirah, 2016). 
Dari hasil penelitian menunjukkan bahwa tidak ada kandungan boraks, tetapi adanya kandungan formalin pada jajanan yang dijual di lingkungan Taman Kurma Kota Lubuklinggau. Kurangnya pengetahuan bagi para penjaja jajanan atau pembeli tentang ciri-ciri dan bahaya jajanan akan kandungan boraks dan formalin sehingga menjadi keuntungan bagi para pedagang. Padahal berbagai peraturan yang telah dibuat, masih belum mampu menghentikan para pedagang untuk tidak menggunakan bahan berbahaya seperti boraks dan formalin pada makanan.

\section{SIMPULAN}

Berdasarkan hasil penelitian yang telah dilakukan, maka dapat disimpulkan bahwa, dari 187 sampel jajanan yang diuji tidak terdapat sampel yang positif mengandung boraks dilingkungan Taman Kurma Kota Lubuklinggau. Sedangkan jajanan yang positif mengandung formalin terdapat 22 sampel, yaitu sosis, mie, bakso dan tahu goreng yang terdapat pada beberapa pedagang dilingkungan Taman Kurma Kota Lubuklinggau. 


\section{DAFTAR PUSTAKA}

Direktorat Pengawasan Produk Dan Bahan Berbahaya. (2014). Waspada boraks dan formalin. Jakarta : Badan POM RI.

Hidayat, Y., \& Muharrami, K. L. (2014). Kecenderungan Pilihan Jajanan Pangan Anak SD Terhadap Jajanan Berformalin. Jurnal Pena Sains, 1(2); 19-26

Junaini., Wibowo, M.A., \& Riyanto. (2016). Uji Kualitatif Kndungan Formaldehid Alami Pada Ikan Patin Jambal (Pangasius Djambal) Selama Penyimpanan Suhu Dingin Menggunakan Tes Kit Antilin. Jkk. 5(3); 812.

Mayasari, D., \& Mardiroharjo, N. (2012). Pengaruh Pemberian Boraks Peroral Sub Akut Terhadap Terjadinya Atrofi Testis Tikus Putih Jantan (Rattus Novergicus Strain Wistar). Jurnal, 8(1); 22-27.

Monijung. F. S., Umboh, L. M. J., \& Sondakh. C. R. (2016). Analisis Kandungan Zat Pengawet Boraks Pada Bakso Yang Disajikan Pada Kios Bakso Permanen Di Kecamatan Malalayang Kota Manado. Jurnal Ilmiah Farmasi-UNSRAT, 5(2); 133-137.

Mudzkirah, I. (2016). Identivikasi Penggunaan Zat Pengawet Boraks Dan Formalin Pada Makanan Jajanan Di Kantin Uin Makasar. Skripsi Universitas Islam Negeri Alaudidin Makasar.

Pandie T, Wuri DA \& Ndaong NA, (2014) Indentifikasi Boraks, Formalin dan Kandungan Gizi serta Nilai Tipe pada Bakso yang Dijual di Lingkungan Perguruan Tinggi di Kota Kupang. Jurnal Kajian Veteriner 2(2); 183192

Paratmanitya, Y., \& Aprilia, V. (2016). Kandungan Bahan Tambahan Pangan Berbahaya Pada Makanan Jajanan Anak Sekolah Dasar di Kabupaten Bantul. Jurnal Gizi dan Dietetik Indonesia, 4( 1); 49-55.

Suntaka, D.F., \& Sondakh, R., (2014). Analisis Kandungan Formalin Dan Boraks Pada Bakso Yang Disajikan Kios Bakso Pemanenan Pada Beberapa Tempat Dikota Bitung Tahun 2014. Artikel Jurnal Kesehatan Masyarakat, 1(4), 39-45. 